\title{
Anaesthetic Management of A Neonate With Glucose - 6 - Phosphatase Dehydrogenase Deficiency- A Case Report
}

\author{
Monika Mahajan, ${ }^{1}$ Usha K Chaudhary, ${ }^{1}$ Manik Sehghal, ${ }^{2}$ Sudarshan Kumar, ${ }^{1}$ \\ Vaibhav Tulsyan ${ }^{1}$ \\ Department of Anaesthesia, Dr. Rajendra Prasad Govt. Medical College, Tanda, Kangra, H.P. India \\ Department of Orthopaedics, Dr. Rajendra Prasad Govt. Medical College, Tanda, Kangra, H.P. India
}

\begin{abstract}
G-6-PD deficiency is one of the most common red blood cell enzymatic defect. It can be asymptomatic clinically or may present as hemolysis, anemia and neonatal hyperbilirubinemia. Drugs which induce haemolysis in these patients are often used in anaesthetic management of patient. Perioperative management of these patient involve avoiding these drugs, adequate pain management to reduce surgical stress, monitoring hemolysis. We present here a case of neonate with G-6-P D deficiency which was operated for septic arthritis under general anesthesia.
\end{abstract}

Keywords: G-6-PD Deficiency, neonatal jaundice, Anaesthesia in G-6-PD deiciency

\section{Introduction}

G-6-P D deficiency is most common disease causing enzyme defect in humans. ${ }^{1} \mathrm{It}$ is a X linked genetic disorder. Both the homozygotes and heterozygotes can be asymptomatic but the hemolysis is more severe in homozygotes. Acute hemolysis is caused by exposure to an oxidative stressor in the form of an infection, oxidative drug or fava beans, the treatment is geared toward avoidance of these and other stressors. Acute hemolysis is self-limited, but in rare instances it can be severe enough to warrant a blood transfusion. ${ }^{2}$

\section{Case Report}

A pre term neonate male aged 16 days, $2.3 \mathrm{~kg}$ was presented to department of pediatrics with complaint of fever for 4 days, swelling right knee with decreased movements for 2 days. Fever was insidious in onset and in the range of $102^{\circ} \mathrm{F}-104^{\circ} \mathrm{F}$ which got relieved on medication. The swelling in right knee was also insidious in onset and associated with restricted movement of right limb. There was no hstory of trauma or vaccination. X Ray knee joint showed joint effusion. USG was advised and USG showed inflammatory changes in knee joint. Patient was planned for arthrotomy of the joint. The child was diagnosed case of G-6-PD deficiency during antenatal period and mother had cholestatic jaundice of pregnancy. Child was born by normal vaginal delivery at POG of 35 weeks 4days with a birthweight of $2.18 \mathrm{~kg}$. Patient had history of neonatal jaundice at the day 3 and received phototherapy. The maximum total serum bilirubin was $14 \mathrm{mg} / \mathrm{dl}$. At the time of presentation to operation theatre, hemoglobin was $8.7 \mathrm{~g} / \mathrm{dl}$, platelet count was $5.28 \mathrm{lac} / \mathrm{dl}$. Serum sodium and potassium were 135.3 and $5.11 \mathrm{mg} / \mathrm{dl}$ respectively. In family history, neonate had a 5 years old brother with similar $\mathrm{h} / \mathrm{o}$ neonatal jaundice who had undergone exchange transfusion twice. The child also developed hearing loss for which he underwent cochlear implant at the age of 5 years.

Anaesthetic management should focus on avoiding the drugs implicated in haemolysis, and monitoring for and treating the haemolysis, should it occur. ${ }^{3}$ The patient was induced with fentanyl $4 \mu \mathrm{g}$ and halothane, atracurium $0.5 \mathrm{mg} / \mathrm{kg}$. Trachea was intubated with $3.5 \mathrm{~mm}$ ID uncuffed tracheal tube. Tube was fixed after confirmation of bilateral air entry. Intraoperative monitoring included electrocardiogram (ECG), oxygen saturation ( $\mathrm{SpO} 2)$, non invasive blood pressure (NIBP) and end tidal carbon dioxide (EtCO2). Anesthesia was maintained with halothane, $\mathrm{O} 2 / \mathrm{N} 2 \mathrm{O}$ mixture and intermittent boluses of atracurium. Blood transfusion was given with $15 \mathrm{ml}$ of cross matched packed cell blood. Trachea was extubated after adequate reversal achieved .The child was watched postoperatively for any deterioration of vitals, urine output and any signs of hemolysis.

\section{Discussion}

G-6-PD is commonest enzyme deficiency worldwide. It is X linked enzymopathy. G-6-PD catalyzes first step of penthose phosphate metabolism which is exclusive source of NADPH (Nicotinamide adenine dinucleotide phosphate). ${ }^{4} \mathrm{NADPH}$ protects cells from oxidative damage. As erythrocytes donot generate NADPH from any other way so are more susceptible to destruction from oxidative stress. ${ }^{5}$ It can present as anemia and neonatal jaundice. Jaundice is considered to be due to an imbalance between production and conjugation of bilirubin. The prevalence of neonatal hyperbilirubinemia is twice that of the general population ${ }^{6}$ in males who carry the defective gene and in homozygous females. It rarely occurs in heterozygous females. ${ }^{7,8}$ 
G-6-PD deficiency should be considered in neonates who develop hyperbilirubinemia within the first 24 hours of life, a history of jaundice in a sibling, bilirubin levels greater than the 95 th percentile, and in asian males. ${ }^{9,10}$ In our patient there was a history of neonatal jaundice at the age of three days for which phototherapy was given to him. There was a similar history of neonatal jaundice in the elder sibling with a progressive sensorineural hearing loss leading to cochlear implant. The G-6-PD levels were done based on high suspicion and the levels were found to be low.

Our aim was to provide safe anesthesia as the anesthetic drugs, NSAIDS and some antibiotics can cause hemolytic anaemia. ${ }^{11}$ The World Health Organization has classified the different G6PD variants according to the magnitude of the enzyme deficiency and severity of haemolysis. Class I variant have severe enzyme deficiency (less than $10 \%$ of normal) and have chronic anemia. Class II variants also have severe enzyme deficiency, but there is usually only intermittent hemolysis. Class III variant have moderate enzyme deficiency (10 to $60 \%$ of normal) with intermittent hemolysis, usually associated with infections or drugs. Class IV variants have no enzyme deficiency or hemolysis. Class V variants have increased increased enzyme activity. Class IV and $\mathrm{V}$ are of no clinical significance. ${ }^{12,13}$

Safe and Unsafe drugs, Chemicals and Anesthetic agents in G6PD-deficient Pop
(Invitro study by Altikatet al ${ }^{\text {14 }}$ )
\begin{tabular}{|l|l|}
\hline Unsafe For Class I, Ii And Iii & Safe For Class Ii And Iii \\
\hline Acetanilid & Acetaminophen \\
\hline Dapsone & Aminopyrine \\
\hline Methylene Blue & Ascorbic Acid \\
\hline Nalidixic Acid & Aspirin \\
\hline Nitrofurantoin & Chloramphenicol \\
\hline Niridazole & Chloroquine \\
\hline Primaquine & Colchicine \\
\hline Toluidine Blue & Diphenhydramine \\
\hline Vitamin K & Isoniazide \\
\hline Sulfacetamide & L-Dopa \\
\hline Sulfamethoxazole & Menadione \\
\hline Sulfanilamide & Paraminobenzoic Acid \\
\hline Phenylhydrazine & Phenacetin \\
\hline Furazolidone & Probenecid \\
\hline Trinitrotoluene & Procainamide \\
\hline Thiazosulfone & Pyrimethamine \\
\hline Phenazoyridine & Quinidine \\
\hline Diazepam & Quinine \\
\hline Isoflurane & Sulfamethoxypyridazine \\
\hline Sevoflurane & Streptomycin \\
\hline & Sulfisoxazole \\
\hline & Trimethoprim \\
\hline & Tripelennamine \\
\hline
\end{tabular}

So in accordance with the study by Altikatet al, ${ }^{14}$ we administered the safe drugs during the induction and maintenance of anesthesia. The use of G-6-PD inhibitors may worsen the health status of the patient. Hence the diagnosis of G-6-PD deficiency in patients with high suspicion along with the avoidance of the harmful drugs is the key to safety.

\section{Conclusion}

G-6-PD deficiency is a common but underdiagnosed enzymopathy. Any male child with neonatal jaundice who has early onset within 24 hours and very high levels of bilirubin should be screened for the G6PD deficiency. The avoidance of the unsafe drugs is the key to safety in these children.

\section{References}

[1]. Smith CL, Snowdon SL. Anaesthesia and G-6-P D.Anaesthesia. 1987;42: 281-88.

[2]. Frank JE.Diagnosis and Management of G6PD Deficiency. Am Fam Physician 2005;72:1277-82.

[3]. Schwartz JP, Cooperberg AA, Rosenberg A. Platelet function studies in patients with glucose-6-phosphate dehydrogenase deficiency. Br J Haematol 1974;27:273-80.

[4]. Peters AL, Van NoordenCJ.Glucose-6-phosphate Dehydrogenase Deficiency and Malaria: Cytochemical Detection of Heterozygous G6PD Deficiency in Women.JHistochemCytochem.. 2009; 57: 1003-1011.

[5]. Massa ED, Federmann S.Ambulatory Anesthesia in Deficiency Glucose 6-phosphate dehydrogenase. The Internet Journal of Anesthesiology. $2006 ; 11: 1-4$.

[6]. Glucose-6-phosphate dehydrogenase; G6PD. Accessed online July 20, 2005, at: http://www3.ncbi.nlm.nih. gov/entrez/dispomim.cgi?id=305900. 
[7]. Kaplan M, Hammerman C, Vreman HJ, Stevenson DK, Beutler e. Acute hemolysis and severe neonatal hyperbilirubinemia in glucose-6-phosphate dehydrogenasedeficient heterozygotes. J Pediatr 2001;139:137-40.

[8]. Corchia C, Balata A, Meloni GF, Meloni T. Favism in a female newborn infant whose mother ingested fava beans before delivery. J Pediatr 1995; $127: 807-8$.

[9]. Bhutani VK, Johnson LH, Keren R. Diagnosis and management of hyperbilirubinemia in the term neonate: for a safer first week. PediatrClin North Am 2004;51:84361.

[10]. American Academy of Pediatrics Subcommittee on Hyperbilirubinemia. Management of hyperbilirubinemia in the newborn infant 35 or more weeks of gestation. Pediatrics 2004;114:297-316.

[11]. Habibi B, Basty R, Chodez S, Prunal A. Thiopentone related immune haemolyticanaemia and renal failure

[12]. Cappellini MD,Fiorelli G.Glucose-6 phophatasedehydrogenase deficiency. Lancet.2008;371:64-74.

[13]. Meloni T, Forteleoni G.Glucose-6-phosphate dehydrogenase deficiency.WHO working group. Bull WHO 1989;67:601-11.

[14]. Altikat S, Cillci M, Buyukokunglu ME. Invitro effects of some anaesthetic drugs on enzymatic activity of human red blood cell glucose-6-phosphate dehydrogenase.Polish J pharmacol.2002;54:67-71. 